\title{
Improving Monolithic Perovskite/Silicon Tandem Solar Cells From an Optical Viewpoint
}

\author{
Klaus Jäger, ${ }^{1,2, *}$ Marko Jošt, ${ }^{1}$ Johannes Sutter, ${ }^{1}$ Philipp Tockhorn, ${ }^{1}$ Eike Köhnen, ${ }^{1}$ \\ David Eisenhauer, ${ }^{1}$ Phillip Manley, ${ }^{1,2}$ Steve Albrecht ${ }^{1}$ and Christiane Becker ${ }^{1}$ \\ ${ }^{1}$ Helmholtz-Zentrum Berlin für Materialien und Energie, Hahn-Meitner Platz 1, 14019 Berlin, Germany \\ ${ }^{2}$ Zuse Institute Berlin, Takustraße 7, 14195 Berlin, Germany \\ *klaus.jaeger@helmholtz-berlin.de
}

\begin{abstract}
Perovskite/silicon tandem solar cells are the most promising concept for a future photovoltaic technology. We report on recent progress from an optical viewpoint and disucss how we achieved more than $25 \%$ device efficiency.
\end{abstract}

OCIS codes: (350.6050) Solar energy; (040.5350) Photovoltaic; (000.4430) Numerical approximation and analysis;

\section{Introduction}

Currently, multi-junction solar cells are the only viable route to surpass the single-junction efficiency limit, which is $29.4 \%$ for silicon [1]. Because of their excellent optoelectronic properties and the possibility to tune their bandgap, perovskites are the most promising material class to be combined with silicon in tandem solar cells. The first monolithic perovskite/silicon tandem cells, where the two subcells are electrically connected in series, were reported in 2015 with $13.7 \%$ power conversion efficiency (PCE) [2]. Recently, $25.5 \%$ and $28 \%$ were reported on lab and industrial scale, respectively [3,4]. The latter PCE exceeds the current single-junction record of $26.7 \%$ [5].

In this contribution, we review the development of perovskite/silicon tandem solar cells in our research center. After presenting optical simulations to assess the potential of these devices, we discuss the steps that were necessary to reach 25.5\% PCE. Finally, we discuss current efforts to texture the silicon wafers in order to reduce reflection losses.

\section{Optical simulations}

Optical simulations are a valuable tool to study how varying the materials and thicknesses of the supporting layers affects the optical performance of the solar cell. Further the effects of changing the perovskite material (and hence bandgap) and (nano)texturing can be investigated. Using the net-radiation method and a thickness optimization, we could show that more than $30 \%$ PCE is theoretically achievable with a fully planar design for an optimal perovskite bandgap around $1.75 \mathrm{eV}$ and a $250 \mu \mathrm{m}$ thick silicon wafer [6]. A back-textured silicon wafer can further increase the short circuit current density by about $1 \mathrm{~mA} / \mathrm{cm}^{2}$ per subcell because of light trapping in silicon at long wavelengths [7].

However, the reflection losses stay significant, because the front of the silicon bottom cell, the top cell and the front interface are planar. These reflective losses can be reduced significantly if the front side of the silicon wafer and the perovskite top cell are textured, as illustrated in Fig. 1(a). Figure 1(b) shows simulations results obtained with the finite element method: a sinusoidal nanotexture with $500 \mathrm{~nm}$ period and $500 \mathrm{~nm}$ amplitude could reduce the reflective losses by $\approx 50 \%[8]$.

\section{Experimental realization of perovskite/silicon tandem solar cells}

To achieve $25.5 \%$ with a planar perovskite top cell, we used a light management (LM) foil, which was placed on top of the tandem device and boosted the short circuit current density from $17.3 \mathrm{~mA} / \mathrm{cm}^{2}$ to $18.5 \mathrm{~mA} / \mathrm{cm}^{2}$, as shown in Figs. 1(c-e) [3]. The $J V$ scans were performed in reverse direction. The LM foil carried the texture of a $\mathrm{KOH}-$ etched silicon wafer and was manufactured using UV-nanoimprint lithography. Further, we designed this cell in an inverted architecture with the electron-selective contact on top. This allowed us to reduce the parasitic absorption losses with respect to the regular design with Spiro-OMeTad as hole-selective front contact [6]. We used the multiple cation, multiple halide composition $\mathrm{Cs}_{0.05}\left(\mathrm{MA}_{0.17} \mathrm{FA}_{0.83}\right) \mathrm{Pb}_{1.1}\left(\mathrm{I}_{0.83} \mathrm{Br}_{0.17}\right)_{3}$ as absorber material. The electron- and hole-selective contacts were $\mathrm{C}_{60}$ and the $p$-type polymer PTAA, respectively. As bottom cell we used a back-side textured and front-side polished rear emitter silicon-heterojunction cell. 
(a)

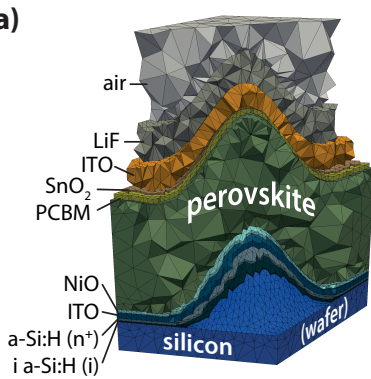

(g)

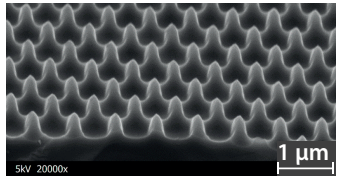

(b)

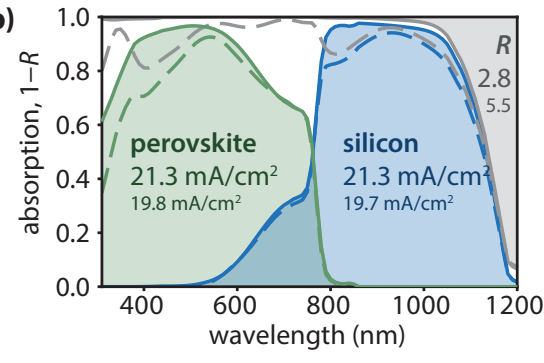

(f)

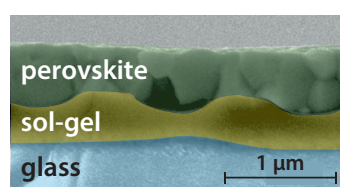

(c)

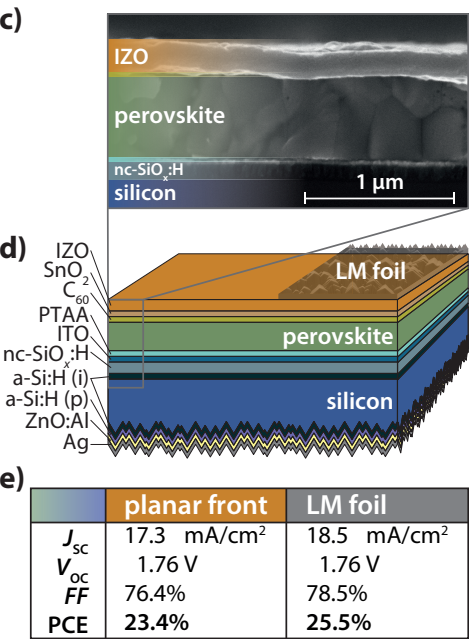

Fig. 1. (a) Grid and (b) results of finite-element simulations of a nanotextured perovskite/silicon solar cell [8]. (c) Scanning electron microscope (SEM) cross section, (d) sketch and (e) external parameters of solar cells with and without light management (LM) foil [3]. SEM pictures of (f) spincoated perovskite on a nanotextured substrate and $(\mathrm{g})$ a sinusoidal nanotexture in silicon.

\section{Developing cells with nanotextured silicon/perovskite interfaces}

Nanotextured silicon/perovskite interfaces can further improve light management. Smooth sinusoidal nanotextures are compatible with spin-coating for perovskite deposition, as shown in Fig. 1(f) [8]. Before building complete tandem devices, fabricating individual subcells with such nanotextures must be optimized. For the bottom cell, the texture is transferred into the silicon wafer by anisotropic reactive ion etching - a scanning electron microscope picture is shown in Fig. 1(g). An isotropic wet chemical etch of the Si wafer stripped off damaged silicon layers yielding minority carrier lifetimes of $700 \mu$ s at $10^{15} \mathrm{~cm}^{-3}$ minority carrier density, which is compatible with good device performance.

For the perovskite top cell, we adjust the processing of the different layers to make it compatible with the nanotextured substrate. Proof-of-principle perovskite single-junction solar cells on sinusoidal nanotextures with peak-to-valley dimensions of up to $400 \mathrm{~nm}$ on glass substrates yield 16.5\% stabilized PCE.

\section{Outlook}

Optical simulations and continuous material improvement allowed us to realize a monolithic perovskite/silicon tandem cell with $25.5 \%$ PCE. Currently, we are working on further improving the material quality of sinusoidally textured silicon wafers and hence on realizing tandem solar cells with nanotextured silicon-perovskite interfaces.

\section{References}

1. A. Richter, M. Hermle, and S. Glunz, "Reassessment of the limiting efficiency for crystalline silicon solar cells," IEEE J. Photovolt. 3, 1184-1191 (2013).

2. J.P. Mailoa, C.D. Bailie, E.C. Johlin, E.T. Hoke, A.J. Akey, W.H. Nguyen, M.D. McGehee, and T. Buonassisi, "A 2-terminal perovskite/silicon multijunction solar cell enabled by a silicon tunnel junction," Appl. Phys. Lett. 106, 121105 (2015)

3. M. Jošt, E. Köhnen, A. B. Morales-Vilches, B. Lipovšek, K. Jäger, B. Macco, A. Al-Ashouri, J. Krč, L. Korte, B. Rech, R. Schlatmann, M. Topič, B. Stannowski, and S. Albrecht, "Textured interfaces in monolithic perovskite/silicon tandem solar cells: advanced light management for improved efficiency and energy yield," Energy Environ. Sci. 11, 3511-3523 (2018).

4. Oxford PV (2018). https://www. oxfordpv.com/news/oxford-pv-perovskite-solar-cell-achieves-28-efficiency.

5. M. A. Green, Y. Hishikawa, E.D. Dunlop, D.H. Levi, J. Hohl-Ebinger, M. Yoshita and A.W.Y Ho-Baillie, "Solar cell efficiency tables (version 53)," Prog. Photovoltaics Res. Appl. 27, 3-12 (2019).

6. K. Jäger, L. Korte, B. Rech, and S. Albrecht, "Numerical optical optimization of monolithic planar perovskite/silicon tandem solar cells with regular and inverted device architectures," Opt. Express 25, A473-A482 (2017).

7. K. Jäger, M. Werth, L. Mazzarella, et al., "Numerical optical optimization of perovskite-silicon tandem solar cells," in Proceedings of the $33^{r d}$ European Photovoltaic Solar Energy Conference and Exhibition, 1057-1060 (2017).

8. D. Chen, P. Manley, P. Tockhorn, D. Eisenhauer, G. Köppel, M. Hammerschmidt, S. Burger, S. Albrecht, C. Becker, and K. Jäger, "Nanophotonic light management for perovskite-silicon tandem solar cells," J. Photonics Energy 8, 022601 (2018). 